- Topical fluoride treatments are safe and effective but should be applied only to patients with decayed smooth surfaces or those at high risk of caries.

- Both APF gel and fluoride varnish are effective and can be recommended for caries prevention in permanent teeth. To maximize fluoride uptake, gels should be applied for 4 minutes.

- The frequency of fluoride application depends on individual risk, but should be at least biannual when indicated.

- Cleaning or prophylaxis is not necessary prior to the application of topical fluorides.

\title{
Prevention. Part 7: Professionally applied topical fluorides for caries prevention
}

\author{
R. Hawkins ${ }^{1}$, D. Locker ${ }^{2}$ and J. Noble ${ }^{3}$; Series Editor E. J. Kay ${ }^{4}$
}

This paper reviews the use of professionally applied topical fluorides (PATF) in caries prevention. PATFs are indicated for children and adults with one or more decayed smooth surfaces and/or those who are at high caries risk. Frequency of administration depends on the patient's caries risk, and is usually every 6 months. The effectiveness of fluoride varnish and gel applications has been well established in caries prevention trials involving permanent teeth. Although both types are effective, varnish may be preferred because it is easier to apply, reduces the risk of fluoride over-ingestion, and has greater patient acceptance. Fluoride foams are similar products to gels, but have not been tested clinically. The use of in-office two-part rinses is not recommended because they have not been proven effective. A cleaning, or prophylaxis, is not necessary before the application of topical fluoride for caries prevention. In conclusion, when used appropriately, PATFs are a safe, effective means of reducing caries risk among high-risk populations.

\section{PREVENTION \\ 1. Smoking cessation advice \\ 2. Dietary advice \\ 3. Prevention of tooth wear \\ 4. Toothbrushing advice \\ 5. Patients requiring osseointegrated oral implant treatment \\ 6. Older dentate patient \\ 7. Professionally applied topical fluorides for caries prevention \\ 8. Pit and fissure sealants in preventing caries in the permanent dentition of children}

${ }^{1}$ Research Associate, ${ }^{2}$ Director, ${ }^{3}$ Research Assistant, Faculty of Dentistry, University of Toronto, Ontario, Canada:

${ }^{4}$ Professor of Dental Health Services Research, University of Manchester Dental Hospital and School, Higher Cambridge Street, Manchester M15 6FH *Correspondence to: Dr Robert Hawkins, Community Dental Health Services Research Unit, Faculty of Dentistry, University of Toronto, Room 521, 124 Edward Street, Toronto, Ontario, Canada M5G $1 \mathrm{G} 6$ E-mail: robert.hawkins@utoronto.ca

\section{Refereed Paper}

doi:10.1038/sj.bdj.4810527

○ British Dental Journal 2003; 195 :

313-317
Caries prevalence among children in western countries has fallen dramatically over the past three decades. ${ }^{1}$ Not all children, however, have experienced the same degree of caries risk reduction, and dental decay remains a significant problem for a substantial minority of high-risk children. The decline in caries prevalence has also not been uniform across tooth surfaces. On a percentage reduction basis, occlusal lesions have declined less than lesions on other tooth surfaces, and make up a higher proportion of the burden of dental caries. ${ }^{2}$

The use of professionally applied topical fluoride (PATF) is one means of preventing caries that is frequently used in private practice and public health settings. In terms of the relative reduction in decayed and filled surfaces, PATF is more effective against smooth surface caries than occlusal caries. ${ }^{3}$ Given the present characteristics of dental caries, the appropriate use of PATF in developed countries must be examined.

Dental personnel have a wide choice of different PATF agents, vehicles, and regimens; and should be aware of the supporting evidence upon which to base their decisions. To gain a better understanding of the use of PATF, the following issues are reviewed: indications for use; caries prevention effectiveness and clinical application of different types of PATF; fluoride ingestion and toxicity; and whether a cleaning is necessary prior to topical fluoride application. The strength of the evidence was classified using the following typology:
Type 1: Systematic review of two or more clinical trials

Type 2: At least one randomized controlled trial Type 3: Non-randomized intervention studies

Type 4: Observational studies

Type 5: Other designs, traditional literature reviews, expert opinion.

\section{WHICH PATIENTS SHOULD RECEIVE PATF?}

PATF should not be applied on a routine basis in dental practices. A patient's susceptibility to caries must first be determined and, based on this information an appropriate preventive care plan should be designed for each individual. The surfaces at risk for decay must also be considered because PATF is more effective against smooth surface caries than against pit and fissure caries.

Topical fluoride applications are indicated for patients with active smooth surface caries and those patients in high caries risk groups (Table 1). This includes special patient groups, such as those undergoing orthodontic treatment. In high-risk groups, evidence indicates an anticaries effect over a 2 -year period, ${ }^{4}$ but PATF application does not make a significant difference in low-to-moderate risk children who also receive water fluoridation and dental sealants. 5,6 From a cost-effectiveness perspective, patients with low caries risk who reside in optimally fluoridated areas are unlikely to benefit from PATF therapy. The number of children that must be treated to prevent one decayed surface is esti- 
Table 1 Indications for use of professionally applied topical fluorides

- Patients who are at high risk for caries on smooth tooth surfaces

- Patients who are at high risk for caries on root surfaces

- Special patient groups, such as: Orthodontic patients

Patients undergoing head and neck irradiation

Patients with decreased salivary flow

- Children whose permanent molars should, but cannot, be sealed

- Not recommended for patients with low caries risk who reside in communities with optimal fluoridation mated at 18 if caries incidence is low, but only 3 for groups with high caries incidence. ${ }^{7}$

A possible indication for the use of PATF is adults with exposed root surfaces. The problem of root caries is likely to increase due to population aging and the increased retention of teeth. However, no clinical studies have yet examined the potential benefits of this intervention.

\section{FLUORIDE VARNISH}

Since their introduction in the 1960s, fluoride varnishes have become the most widely used PATF in Europe. ${ }^{8,9}$ The most common types of $\mathrm{NaF}$ varnish are Duraphat $(2.2 \% \mathrm{~F})$ and Fluor Protector $(0.1 \% \mathrm{~F})$. The advantage of varnish is its ability to adhere to tooth surfaces, which prolongs contact time between fluoride and enamel and improves fluoride uptake into the surface layers of enamel.

\section{Caries prevention}

For the permanent dentition, the anti-caries effect of fluoride varnish has been confirmed in a number of clinical trials. In a meta-analysis on the caries preventive effect of Duraphat varnish, eight studies were identified that were of high quality and provided Type 1 evidence. ${ }^{10,11}$ Based on these studies, it was estimated the use of varnish resulted in a 38\% reduction in caries increment (95\% CI $=19-57 \%)$. In a second analysis, which included six additional studies, the estimated effect was again a $38 \%$ reduction $(95 \% \mathrm{CI}=25-50 \%)$. Studies involved subjects ranging in age from 6-to-15 years; the application frequency was most often biannual; and the majority of studies were continued for at least 2 years.

Recent findings are consistent with the con-

\section{Table 2 Procedure for the application of fluoride varnish}

- Remove excess moisture from teeth with a cotton swab, cotton roll, or air syringe. Meticulous drying of the teeth is not necessary because the varnish will set in presence of moisture.

- Dispense $0.5-1 \mathrm{ml}$ of varnish in a dappen dish. This should be enough for the entire dentition.

- Apply varnish as a thin layer using a disposable brush, or cotton pellet.

- The entire tooth surface must be treated, but do not place large amounts on tooth surfaces. Avoid applying varnish to gingival tissues because of the risk of contact allergies.

- No drying is required after application because varnish sets in a few seconds.

- The patient's mouth can be closed immediately following treatment.

- Patients can only have fluids or soft foods during the next four hours. Hard foods should be avoided.

- Patients should not brush their teeth for the rest of the day. This enhances the uptake of fluoride into the tooth structure.

Note: Varnish is contraindicated for persons with a history of allergies or asthma. clusions of the meta-analysis. In a high-risk community, children who received at least two varnish applications per year showed a 37\% reduction in mean caries increment for a 4-year period compared with a control group. ${ }^{12}$ Similarly, the effectiveness of fluoride varnish was supported in 24- and 48-month comparison studies of varnish and dental sealants. ${ }^{13,14}$ In the 24-month report, compared with the control group, the use of fluoride varnish resulted in a $66 \%$ reduction in DMFS on non-fissured surfaces and a 38\% reduction on fissured surfaces. However, in both reports, dental sealants were found to have superior performance for the prevention of decay.

The only direct comparison of the effectiveness of fluoride varnish and gel, in a developed country, showed no statistically significant differences between the treatment groups ( $\mathrm{NaF}$ varnish and APF gel). ${ }^{15}$ In this 3-year RCT study involving 12-13-year-olds, the mean total DMFS increments were 3.1 and 3.6 for the varnish and gel groups, respectively. The findings suggested varnish was as effective as gel for caries prevention.

For the primary dentition, the evidence is limited and only two randomized controlled trials have been conducted. Several studies of fluoride varnish have reported prevented fraction percentages of between 30-44\%, ${ }^{16,17}$ but findings have been inconsistent and most comparisons have not found significant differences. Recent studies have also found that varnish may slow the progression of early enamel caries in the primary dentition. ${ }^{18,19}$ However, at present there is insufficient evidence with which to assess caries prevention effectiveness in primary teeth.

No definite conclusions can yet be drawn about the relative effectiveness of Duraphat and Fluor Protector varnishes.

\section{Clinical application}

PATFs must be reapplied at regular intervals to be effective and the frequency will depend on the risk level of the patient. Different application frequencies have been effective in clinical trials, but it is generally recommended that fluoride varnish be applied at least every 6 months.

The application of varnish is straightforward and can be done by a dental hygienist or a trained assistant (Table 2). ${ }^{20}$ The entire process takes between 3-5 minutes per patient, depending upon the number of teeth present. Varnish is generally well accepted by dental personnel and patients, and has been found to be preferred to fluoride gel by both groups. ${ }^{21}$ Dental hygienists found varnish easier and faster to apply, and allowed for better control of moisture and fluoride ingestion.

No common or serious side effects of varnish use have been reported. As a precaution, it is contraindicated in asthmatic patients due to possible allergic reactions. The temporary tooth discoloration caused by Duraphat varnish is objectionable to some patients, but is readily removed upon brushing. 


\section{FLUORIDE GEL AND FOAM}

Fluoride gel applications are more commonly used in the US and Canada. Gels are applied in Styrofoam mouth trays, and the most widely used gel is 1.23\% F acidulated phosphate fluoride (APF). Fluoride foams are relatively recent products that are similar to gels, but have not been assessed in clinical trials.

\section{Caries prevention}

The effectiveness of PATF gels has been documented in numerous clinical studies. In a metaanalysis of fluoride gel trials, van Rijkom et al. included nine studies (ten comparisons) of professionally applied gels published between 1970 and $1992 .{ }^{7}$ The overall average prevented fraction was $22 \%(95 \% \mathrm{CI}=18-25 \%)$ indicating good evidence of effectiveness in permanent teeth. All of the PATF studies used APF gel, application frequency varied from 1-2 times per year, and the ages of subjects ranged from 6-15 years.

No significant differences were found between application frequencies, but this result should be interpreted with caution because no head-to-head comparisons were included. Although two randomized trials have found no difference between annual and biannual application frequencies, ${ }^{22,23}$ these studies could not control for the number of additional PATF applications which may have been received from private dentists not involved in the studies. Due to this possibility, there is a lack of evidence that annual applications are effective for caries prevention, and biannual applications are advisable.

A recently published Cochrane Review of fluoride gels included 25 studies, 14 involving PATF. ${ }^{24}$ Based on these studies, the DMFS pooled prevented fraction was 28\% (95\% CI $=19-37 \%)$. The authors found insufficient information to evaluate application frequency, or caries prevention in the primary dentition.

Fluoride foams have not been assessed in clinical trials. Their characteristics are likely similar to gels because the same method of application is used, their fluoride concentrations are comparable, and fluoride enamel uptake is better. $^{25}$

\section{Clinical application}

The frequency of gel application varies based on the caries risk level of the patient, and is usually provided at least every 6 months. Gel application is uncomplicated and can be performed by a dental auxiliary (Table 3).

The four-minute application of fluoride gel is recommended based on studies of enamel fluoride uptake. ${ }^{26,27}$ When contact time is reduced to one minute, enamel fluoride uptake is significantly less. No clinical data support the 1 minute application of any product when used in the typical 6-month recall system. Nevertheless, many dental practices have reported applying fluoride gel for only 1 minute. ${ }^{28}$

Gel application is acceptable to most

\section{Table 3 Procedure for the application of fluoride ge}

- Mouth trays should be tried in the patient's mouth. It may be necessary to adapt or trim trays.

- Patient should be seated upright and suction should be used during the procedure.

- Teeth should be air-dried before gel application. For caries prevention, cleaning or prophylaxis is unnecessary prior to PATF.

- Enough gel, or foam, should be used to completely cover the teeth, but should be no more than 2-2.5 grams per tray or $40 \%$ of the tray's volume.

- Upper and lower trays should be inserted separately.

- Fluoride should be applied for 4 minutes, not 1 minute.

- Patient should expectorate for 1-2 minutes after tray removal.

- Patient should not rinse, eat, or drink for at least 30 minutes after the procedure. Note: For patients with porcelain or resin restorations, neutral sodium fluoride is recommended to prevent etching of restorations.

patients. However, some children find the experience to be unpleasant, and gagging may occur with young children. The most common adverse effect is over-ingestion, which can lead to nausea and vomiting. The inadvertent ingestion of gel can be prevented by the use of a suction device, seating the patient upright, not overfilling trays, and using well-fitted trays.

\section{IN-OFFICE FLUORIDE RINSES}

Two-part fluoride rinses are being used more frequently in North American practices instead of gels or foams. ${ }^{28}$ These rinses consist of two fluorides, APF and stannous fluoride, which are mixed or used concurrently; and are different from the mouthrinses used in school-based programs or home-use. ${ }^{29}$

Two-part rinses are marketed as a preventive agent that is better tolerated than tray applications and reduces fluoride ingestion. However, none of these claims has been supported. First, it is unlikely these products are as effective as other agents because the fluoride concentrations are much lower compared with APF gel $(1,500-3,000$ ppm vs. 12,300 ppm). Caries prevention effectiveness has not been reported in any randomized clinical trials. Second, the risk of ingestion is greater because rinses can be more easily swallowed. These rinses should never be used for young children because acute fluoride toxicity could result if they were swallowed. Lastly, it is doubtful whether in-office rinses are better tolerated by patients because of their sharp, metallic taste.

In-office fluoride rinses are not recommended for caries prevention because other effective ant-caries PATF products are readily available.

\section{FLUORIDE INGESTION AND TOXICITY}

Fluoride applications must be carefully monitored because the potential for overingestion and toxicity does exist. Fluoride is rapidly absorbed in the gastrointestinal tract and young children are particularly vulnerable. Patients should not be left unattended during the application of PATF.

A considerable amount of fluoride may be retained after gel application, even if suction

\section{Studies of enamel fluoride uptake suggest that a four-minute application is to be recommended. Reducing contact time significantly reduces enamel fluoride uptake}




\section{A cleaning or prophylaxis is not necessary prior to the application of topical fluorides}

devices are used (on average $7.7 \mathrm{mg}$ in children). ${ }^{30}$ The risk of fluoride ingestion with fluoride foam is reduced, compared with gel, because a smaller amount is needed for applications. The exposure to and retention of fluoride foam by the patient may be significantly less compared with APF gel application. ${ }^{25}$

Fluoride varnish has a high fluoride concentration, but its safety is acceptable. Varnish is fast setting, fluoride is slowly released, and a small amount is needed for the complete dentition. Measurements of fluoride after topical treatments with varnish show levels far below those considered toxic. ${ }^{31,32}$ Consequently, varnishes may be a better alternative to fluoride gels, especially for young children. ${ }^{8}$

PATF is not a risk factor for dental fluorosis when used at 6-month intervals, and if precautions are taken to minimize ingestion. ${ }^{30}$

\section{IS A CLEANING NECESSARY PRIOR TO THE APPLICATION OF TOPICAL FLUORIDE?}

Several clinical studies have reported that a cleaning, or prophylaxis, is not necessary before the application of topical fluorides. ${ }^{23,33,34}$ No significant differences in caries reduction were found between patients who received a cleaning before application of PATF and those patients who did not receive a cleaning.

\section{SUMMARY}

The following is a summary of the important scientific facts and principles concerning the use of PATF:

- PATF should not be applied on a routine basis in dental practices. Fluoride applications are only indicated for patients with decayed smooth surfaces and those at high caries risk (Type 1)

- Both APF gel and fluoride varnish are effective and can be recommended for caries prevention in permanent teeth (Type 1)

- Frequency of PATF application will depend on the risk level of the patient, but should be provided at least on a biannual basis when indicated (Type 1)

- For gel applications, gel should be retained in the mouth for 4 minutes (Type 5)

- During topical fluoride application, precautions must be taken to minimize fluoride ingestion (Type 5), and

- No cleaning or prophylaxis is necessary before the application of topical fluoride for caries prevention (Type 1)

Table 4 provides a comparison of the different types of PATFs considered in this review. Evidence indicates varnish and gel applications are similar in caries prevention effectiveness in permanent teeth. Although no clinical trials support the use of fluoride foam, it is likely to be equivalent to fluoride gel use for caries prevention. For several reasons, fluoride varnishes may be a better alternative to fluoride gels, particularly for young children. These reasons include reduced risk of fluoride over-ingestion, greater patient acceptability, and faster and easier application. The use of in-office two-part rinses is not recommended. When used appropriately, professionally applied topical fluorides are a safe, effective means of reducing caries risk among high-risk populations.

1. Anderson R J. Changes in dental caries experience of 12 year-old school children in two Somerset schools: a review after an interval of 30 years. Br Dent J 1995:179:125-129.

2. LiSH, Kingman A, Forthofer R, Swango P. Comparison of tooth surface-specific dental caries attack patterns in US schoolchildren from two national surveys. J Dent Res 1993; 72:1398-1405.

3. Woodward G L, Lewis D W. The use of professionally applied topical fluorides in the North York Public Dental Program. Quality Assurance Report No. 8, Community Dental Health Services Research Unit, University of Toronto, 1995

4. Olivier M, Brodeur J M, Simard P L. Efficacy of APF treatments without prior toothcleaning targeted to high-risk children. Community Dent Oral Epidemiol 1992; 20: 38-42.

5. Bagramian R A. A 5-year school-based comprehensive preventive program in Michigan, U.S.A. Community Dent Oral Epidemiol 1982; 10: 234-237.

6. Bohannan H M, Klein S P, Disney J A, Bell R M, Graves R C,

\begin{tabular}{|c|c|c|c|c|c|}
\hline & Caries prevention & Clinical application & Fluoride ingestion & Cost & Acceptability \\
\hline Varnish & $\begin{array}{l}\text { Effective in } \\
\text { high risk } \\
\text { children } \\
\text { (permanent } \\
\text { teeth) }\end{array}$ & $\begin{array}{l}\text { Easy } \\
\text { Application } \\
\text { time varies }\end{array}$ & $\begin{array}{l}\text { Lowest risk } \\
\text { Moisture can be } \\
\text { better controlled } \\
\text { than gel or foam }\end{array}$ & $\begin{array}{l}\text { Most } \\
\text { expensive }\end{array}$ & $\begin{array}{l}\text { Preferred by } \\
\text { patients and } \\
\text { hygienists, } \\
\text { compared with gel }\end{array}$ \\
\hline Gel & $\begin{array}{l}\text { Effective in } \\
\text { high risk } \\
\text { children } \\
\text { (permanent } \\
\text { teeth) }\end{array}$ & $\begin{array}{l}\text { Easy } \\
\text { Four-minute } \\
\text { application } \\
\text { time }\end{array}$ & $\begin{array}{l}\text { \% retained can be } \\
\text { substantial } \\
\text { Procedure must be } \\
\text { followed to reduce } \\
\text { risk }\end{array}$ & Low cost & $\begin{array}{l}\text { Well-tolerated by } \\
\text { most patients, but } \\
\text { varnish is preferred }\end{array}$ \\
\hline Foam & $\begin{array}{l}\text { Not clinically } \\
\text { tested } \\
\text { Likely similar } \\
\text { to gel }\end{array}$ & $\begin{array}{l}\text { Easy } \\
\text { Four-minute } \\
\text { application } \\
\text { time }\end{array}$ & $\begin{array}{l}\text { Risk of over- } \\
\text { ingestion is less } \\
\text { compared with gel }\end{array}$ & Low cost & $\begin{array}{l}\text { Not formally } \\
\text { assessed } \\
\text { Likely to be similar } \\
\text { to gel }\end{array}$ \\
\hline $\begin{array}{l}\text { In-office } \\
\text { two-part } \\
\text { rinses }\end{array}$ & $\begin{array}{l}\text { Not clinically } \\
\text { tested }\end{array}$ & $\begin{array}{l}\text { Most } \\
\text { convenient }\end{array}$ & $\begin{array}{l}\text { Greater risk of } \\
\text { swallowing } \\
\text { Not recommended } \\
\text { for young children }\end{array}$ & $\begin{array}{l}\text { Least } \\
\text { expensive }\end{array}$ & $\begin{array}{l}\text { Not formally } \\
\text { assessed }\end{array}$ \\
\hline
\end{tabular}


Foch C B. A summary of the results of the National Preventive Dentistry Demonstration Program. J Can Dent Assoc 1985; 51: 435-441.

7. van Rijkom H M, Truin G J, van't Hof M A. A meta-analysis of clinical studies on the caries-inhibiting effect of fluoride ge treatment. Caries Res 1998; 32: 83-92.

8. Bawden J W. Fluoride varnish: a useful new tool for public health dentistry. J Public Health Dent 1998; 58: 266-269.

9. Beltran-Aguilar E D, Goldstein J W, Lockwood S A. Fluoride varnishes: a review of their clinical use, cariostatic mechanism, efficacy and safety. J Am Dent Assoc 2000; 131: 589-596.

10. Helfenstein U, Steiner M. Fluoride varnishes: a meta-analysis. Community Dent Oral Epidemiol 1994; 22: 1-5.

11. Helfenstein U, Steiner M. A note concerning the caries preventive effect of Duraphat. Community Dent Oral Epidemiol 1994; 22: 6-7.

12. Zimmer S, Robke FJ, Roulet J F. Caries prevention with fluoride varnish in a socially deprived community. Community Dent Oral Epidemiol 1999; 27: 103-108.

13. Bravo M, Baca P, Llodra J C, Osorio E. A 24-month study comparing sealant and fluoride varnish in caries reduction on different permanent first molar surfaces. J Public Health Dent 1997; 57: 184-186.

14. Bravo M, Garcia-Anllo I, Baca P, Llodra J C. A 48-month survival analysis comparing sealant (Delton) with fluoride varnish (Duraphat) in 6- to 8-year-old children. Community Dent Oral Epidemio/ 1997; 25: 247-250.

15. Seppa L, Leppanen T, Hausen H. Fluoride varnish versus acidulated phosphate fluoride gel: a 3-year clinical trial. Caries Res 1995; 29: 327-330.

16. Holm A K. Effect of fluoride varnish (Duraphat) in preschool children. Community Dent Oral Epidemiol 1979; 7: 241-245.

17. Twetman S, Petersson L G. Prediction of caries in pre-schoo children in relation to fluoride exposure. Eur J Oral Sci 1996; 104: 523-528.

18. Peyron M, Matsson L, Birkhead D. Progression of approxima caries in primary molars and the effect of Duraphat treatment. Scand J Dent Res 1992; 100: 314-318.

19. Autio-Gold J T, Courts F. Assessing the effect of fluoride varnish on early enamel carious lesions in the primary dentition. J Am Dent Assoc 2001; 132: 1247-1253.

20. Blinkhorn A, Davies R. Using fluoride varnish in the practice BrDent J 1998; 185: 280-281.
21. Warren D P, Henson H A, Chan J T. Dental hygienist and patient comparisons of fluoride varnishes to fluoride gels. J Dent Hyg 2000; 74: 94-101.

22. Horowitz HS, Doyle J. The effect of dental caries on topically applied acidulated phosphate fluoride: results after three years. J Am Dent Assoc 1971; 82: 359-365.

23. Johnston $D$ W, Lewis $D$ W. Three-year randomized trial of professionally applied topical fluoride gel comparing annual and biannual applications with/without prior prophylaxis. Caries Res 1995; 29: 331-336.

24. Marinho V C C, Higgins J PT, Logan S, Sheiham A. Fluoride gels for preventing dental caries in children and adolescents (Cochrane Review). In: The Cochrane Library, Issue 2, 2002. Oxford: Update Software.

25. Whitford G M, Adair S M, McKnight C M, Perdue E C, Russell CM. Enamel uptake and patient exposure to fluoride: comparison of APF gel and foam. Pediatr Dent 1995; 7 : 199-203.

26. Wei S H Y, Hattab F N. Fluoride retention following topical application of a new APF foam. Pediatr Dent 1989; 11 : 121-124.

27. Wei S H Y, Lau E W S, Hattab F N. Time dependence of ename fluoride acquisition from APF gels. II. In vivo study. Pediatr Dent 1988; 10: 173-177

28. Warren D P, Hensen H A, Chan J T. A survey of in-office use of fluorides in the Houston area. J Dent Hyg 1996; 70: 166-171.

29. Ripa L W. Topical fluorides: a discussion of risks and benefits. J Dent Res 1987; 66: 1079-1083.

30. Johnston D W. Current status of professionally applied topical fluorides. Community Dent Oral Epidemio/ 1994; 22: 159-163.

31. Ekstrand J, Koch G, Petersson L G. Plasma fluoride concentration and urinary fluoride excretion in children following application of the fluoride-containing varnish Duraphat. Caries Res 1980; 14: 185-189.

32. Roberts J F, Longhurst P. A clinical estimation of the fluoride used during application of a fluoride varnish. Br Dent J 1987 162: 463-466.

33. Houpt M, Koenigsberg S, Shey Z. The effect of prior tooth cleaning on the efficacy of topical fluoride treatment: twoyear results. Clin Preven Dent 1983; 5: 8-10.

34. Ripa LW, Leske GS, Sposato A, Varma A. Effect of prior tooth cleaning on bi-annual professional acidulated phosphate fluoride topical fluoride gel-tray treatments: results after three years. Caries Res 1984; 18: 457-464. 